\title{
Correspondance
}

\section{Lawnmower neuritis: an unusual occupational hazard}

M eralgia paresthetica is a purely sensory neuropathy caused by irritation or compression of the lateral femoral cutaneous nerve of the thigh, usually at the point where the nerve enters the thigh under the inguinal ligament. The condition is frequently misdiagnosed, and its true incidence may be higher than 4.3 per 10000 person-years. ${ }^{1}$ The exact cause of meralgia paresthetica is uncertain, but common contributing causes include obesity, tight clothing around the belt area, ${ }^{2-4}$ pregnancy and trauma. We present a case of meralgia paresthetica related to the patient's occupation.

A 32-year-old gardener presented with a 2-year history of intermittent burning pain along the anterolateral aspect of his left thigh. This problem occurred only when he used a ride-on lawnmower. He had gained weight (to $121 \mathrm{~kg}$ ), and his broad utility belt dug into his sides whenever he sat on the lawnmower in the posture shown in Fig. 1. His symptoms were triggered and exacerbated whenever he drove over uneven ground. Examination revealed sensory disturbances in the distribution of the lateral femoral cutaneous nerve (Fig. 1 and Fig. 2). Palpation around the left anterior superior iliac spine elicited tingling in the anterolateral thigh. The results of all investigations, including spino-pelvic MRI, were normal. We diagnosed meralgia paresthetica, and treated the patient conservatively.

Several months later, the patient changed jobs. As a warden, he did not have to use a lawnmower, wore a narrower belt and lost weight. He is now symptom-free.

There are very few reported cases of occupation-associated meralgia paresthetica. ${ }^{3}$ This case highlights the

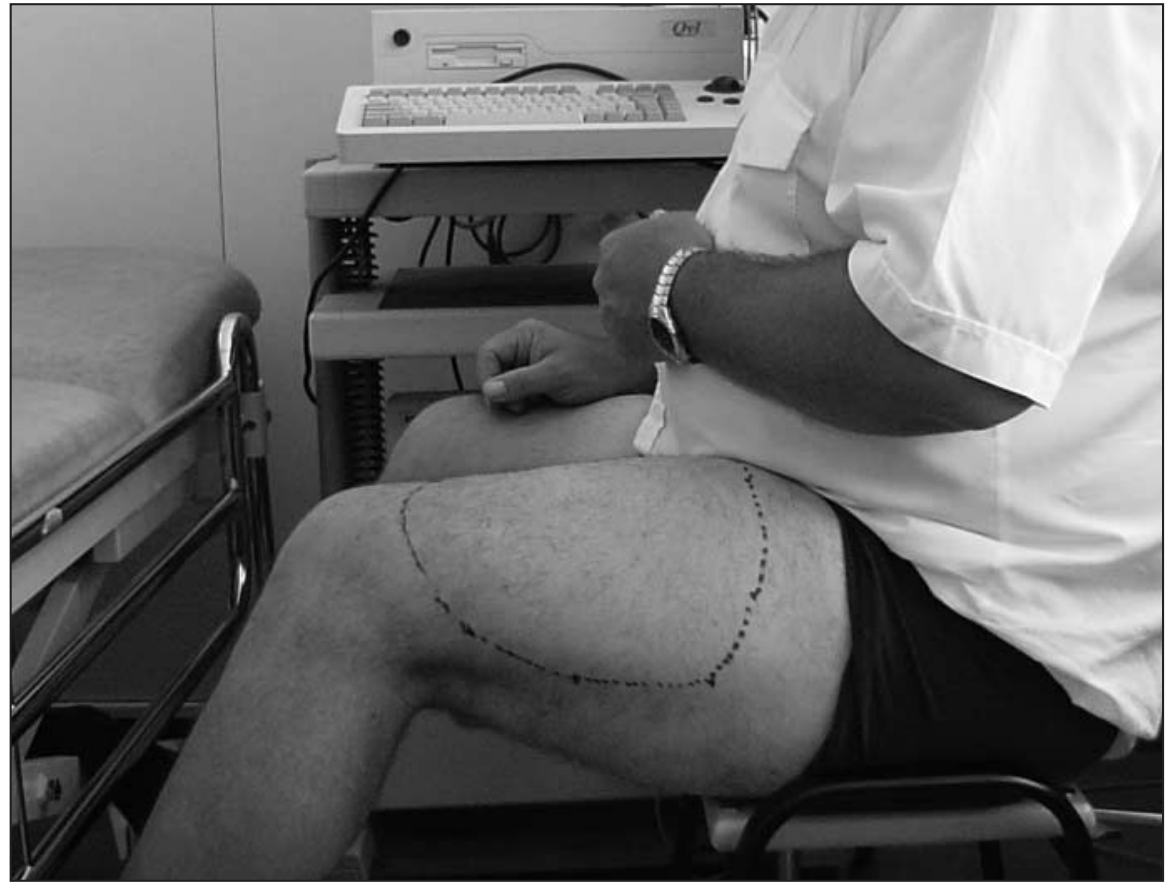

Fig. 1: Patient sitting in posture used for operating ride-on lawnmower. The dotted line on the patient's thigh delineates the area of pain, which corresponds to the distribution of the lateral femoral cutaneous nerve. need to obtain a complete occupational history and to consider the possibility of meralgia paresthetica in patients presenting with thigh pain, as misdiagnosis may lead to unnecessary and inappropriate treatment. ${ }^{5}$

\section{Hu Liang Low}

Neurosurgical Registrar

\section{George Stephenson}

Consultant Neurosurgeon

University Hospital of Wales

Cardiff, UK

\section{References}

1. van Slobbe AM, Bohnen AM, Bernsen RM, Koes BW, Bierma-Zeinstra SM. Incidence rates and determinants in meralgia paresthetica in general practice. 7 Neurol 2004;251(3):294-7.

2. Parmar MS. Hiphuggers' tingly thighs [letter] CMA7 2003;168(1):16.

3. Kotler D. Meralgia paresthetica. Case report in policewoman. 7AAPA 2000;13(10):39-42, 47.

4. Boulware DR. Backpacking-induced paresthesias. Wilderness Environ Med 2003;14(3):161-6.

5. Kallgren MA, Tingle LJ. Meralgia paresthetica mimicking lumbar radiculopathy. Anesth Analg $1993 ; 76(6): 1367-8$

\section{DOI:10.1503/cmaj.1041056}

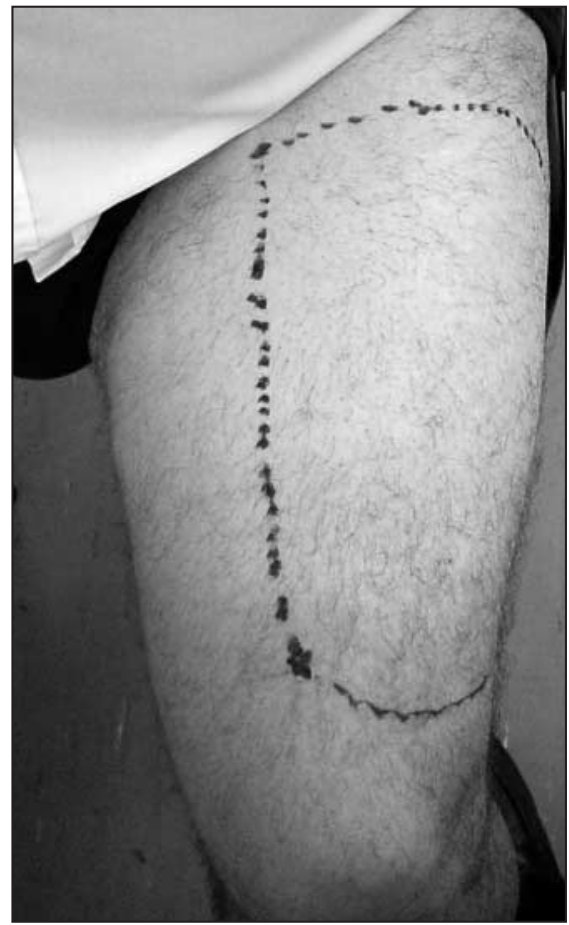

Fig. 2: Another view of the patient's thigh showing the distribution of the pain. 